\title{
Redes comerciales y estrategias matrimoniales. La mujeres en el comercio del Galeón de Manila (siglos XVII-XVIII)
}

\author{
Inmaculada ALvA \\ Universidad de Navarra \\ ialva@unav.es
}

Recepción: 3 de febrero de 2015 / Revisión: 25 de marzo de 2015

Aceptación: 30 de marzo de 2015 / Publicación: Diciembre de 2016

\begin{abstract}
RESUMEN
Durante el período colonial, el comercio en Filipinas estuvo centrado en el monopolio del Galeón de Manila, una ruta comercial que, desde 1593, unía el Oriente con el Occidente. En medio de un mundo de soldados y ricos comerciantes, no faltaron mujeres que encontraron la forma de desarrollar una actividad productiva. Desde principios del siglo XVII, las viudas tenían concedido el privilegio de participar en la carga del galeón, para facilitar su sostenimiento económico. Algunas prefirieron vender su participación a otros comerciantes, pero también las hubo que invirtieron su capital personalmente en este comercio, utilizando las redes y contactos comerciales establecidos por sus difuntos maridos. La actividad mercantil que desarrollaron fue muy similar a la de los comerciantes establecidos en las islas.

El presente trabajo trata de rescatar del olvido a una buena parte de esas mujeres, especialmente a aquellas que no se limitaron a vivir de su pensión, sino que lucharon por mantener y acrecentar los negocios de sus maridos. Permite comprender el papel de la mujer desde una nueva perspectiva, en el contexto de una sociedad que aparentemente les dificultaba el desenvolvimiento de este tipo de habilidades profesionales. A través de algunos ejemplos, se mostrará la forma como se implicaron en esas empresas mercantiles, las relaciones que entablaron y las estrategias matrimoniales que desarrollaron para asegurar su fortuna y patrimonio.
\end{abstract}

Palabras clave: Filipinas, Manila, mujeres comerciantes, redes familiares, comercio, Galeón de Manila, siglos XVII y XVIII.

\section{Commercial Networks and Marriage Strategies. Women in the Commerce of the Manila Galleon (1 $7^{\text {th }}-18^{\text {th }}$ Centuries)}

\begin{abstract}
During the colonial period, commerce in the Philippines was channeled through the monopoly of the Manila Galleon, a commercial route that linked the East and the West since 1593. In a world of soldiers and wealthy merchants, there was no lack of women who saw in this trade the means to develop a productive activity. From the beginning of the $17^{\text {th }}$ century, widows were granted the privilege of participating in the provision of the galleon, as a way to facilitate their economic subsistence. Some chose to sell their participation to other merchants, but others invested their capital personally in this trade, using their networks and the commercial contacts established by their deceased spouses. The mercantile activity they developed was similar to that of the merchants established on the Islands.
\end{abstract}


This study attempts to rescue a good part of these women from oblivion, especially those that chose to maintain and increase their spouse's business, rather than limit their livelihoods to their pensions. The study allows for an understanding of the role of women from a new perspective, within the context of a society that otherwise hindered their development in this type of professional activity. Through case studies, the article demonstrates how they became implicated in these mercantile ventures, the relations they established, and the marriage strategies they developed in order to secure their fortunes and patrimony.

Keywords: Philippines, Manila, female merchants, familiar networks, commerce, Manila Galleon, $17^{\text {th }}$ and $18^{\text {th }}$ centuries.

Sumario: 1 . Introducción. 2. Situación de las viudas en el contexto colonial hispanoamericano (y filipino). 3. Las viudas en Manila y el comercio del Galeón. 4. María Rosa Rayo Doria: viudedad y relaciones familiares. 5. Conclusiones. 6. Referencias bibliográficas.

\section{INTRODUCCIÓN}

La vida en Manila, durante la época colonial, participaba de todas las características de una ciudad fronteriza. Su estratégica situación entre dos mundos hizo prevalecer el carácter militar. Más si se tiene en cuenta que la ciudad de Manila era un emplazamiento apetecido por chinos, holandeses e ingleses, quienes pusieron muchas veces en peligro la hegemonía española en esas tierras. Pero por encima de estas características, fue el comercio lo que dio a Manila ese ambiente exótico y peculiar que la convirtió en puente entre el Oriente y el Occidente, en un punto neurálgico para el comercio entre chinos y españoles. Y no solo chinos, pues muy pronto, a la masiva población sangley que se estableció en el Parián, se sumaron otros pueblos procedentes de Japón, Siam, Borneo, India y otros lugares del Lejano Oriente.

Aunque la pequeña sociedad española establecida en Manila reprodujo las formas y estilos de vida de la metrópoli y de otras ciudades coloniales, la lejanía de los centros de poder, su carácter militar y la importancia del comercio le otorgaron unas características específicas que la distinguían de otros municipios. Ciertamente, los españoles vivían intramuros de la ciudad y apartados de los otros pueblos, pero el intercambio e influencia cultural no dejó de producirse. Si Manila era una frontera entre dos mundos, igualmente puede decirse que la ciudad se fue convirtiendo con el tiempo en una encrucijada de culturas ${ }^{1}$.

En este contexto, el comercio establecido desde 1593 entre Filipinas y Nueva España a través del llamado Galeón de Manila ${ }^{2}$ fue de una importancia primordial para la economía filipina y jugó un papel relevante en las relaciones entre Oriente y Occidente. A lo largo de todo el período colonial, los vecinos de Manila aprovecharon el privilegio del monopolio sobre la carga del galeón, para participar en una red co-

1 Es muy sugerente en este sentido la descripción que el profesor García-Abásolo hace de la ciudad de Manila como línea fronteriza y puente entre dos mundos. Cfr. GARCíA-ABásolo, 2011, pp. 78-87. Para el intercambio cultural entre los distintos pueblos, ALVA, 2014, pp. 207-221.

2 Utilizaré el término "Galeón de Manila" para referirme a la línea comercial, mientras que "galeón" con minúscula hará referencia a los barcos que se utilizaron para la carga. 
mercial de carácter internacional que se convertiría en el centro de la vida social y económica de Manila.

Desde 1593, cualquier vecino inscrito en el libro de registros de la ciudad tenía derecho a participar en este lucrativo negocio. Cada año, en cuanto se calibraba la capacidad de la bodega de la nao, la Junta de Repartimiento repartía las piezas que cada vecino podía cargar atendiendo a un orden en el que primaban antigüedad, méritos y, sobre todo, fortuna. Los vecinos recibían una boleta con el número de piezas asignadas. Una pieza era un fardo con unas medidas concretas, que contenía mercancías como sedas, especias, artesanías de madera o marfil y también productos de la tierra, como las mantas de Ilocos. El valor de cada pieza era muy variable, aunque en los años que abarca este artículo, 1691-1708, solía tasarse en 150 pesos; excepto algún año que descendió a 120 pesos $^{3}$. Una vez que las naos eran cargadas y partían rumbo a Nueva España, no restaba sino esperar a que estas llegaran a buen puerto y volvieran con la plata, fruto de la venta de los productos en la feria de Acapulco. Una plata que, en general, se invertía de nuevo en la compra de más bienes para cargar en el galeón de ese año.

El objetivo de este trabajo es llamar la atención sobre un grupo de la población hispana (peninsular o ya criolla) no suficientemente conocido, el de las mujeres ${ }^{4} \mathrm{y}$, dentro de ellas, las viudas que se dedicaron al comercio, aprovechando que contaban con una participación en la carga del Galeón.

Las fuentes utilizadas proceden en su mayor parte del Archivo General de Indias de Sevilla. La actividad de las mujeres en la Filipinas colonial aparece de forma salpicada en las relaciones de méritos y servicios contenidas en las cartas de personas particulares para solicitar encomiendas; en los testamentos incluidos en diversos expedientes de reclamaciones de deudas a la Corona y, por supuesto, en las listas de repartimientos de toneladas del Galeón de Manila, contenidos en los expedientes de los juicios de residencia a los gobernadores o en las averiguaciones sobre mercancías embarcadas fuera de registro. No existe, por tanto, una fuente homogénea que permita obtener datos de forma sistemática, sino que se trata de sacar el máximo partido a la información dispersa que la documentación va mostrando. En este sentido, me han resultado de gran ayuda las listas de reparto de piezas de los expedientes del juicio de residencia del gobernador Fausto Cruzat y Góngora y de la reclamación de los regidores para que se les conservara el privilegio de cargar una tonelada en razón de su cargo. He contado así con una línea cronológica lo suficientemente amplia para ver la continuidad de las inversiones mercantiles de algunas mujeres a finales del siglo XVII y principios del XVIII.

He podido obtener datos adicionales de algunas viudas en la documentación de protocolos del Archivo Nacional de Filipinas y en las informaciones matrimoniales y de fundación de capellanías del Archivo Diocesano de Manila.

\footnotetext{
3 Una descripción detallada del valor y medidas de las piezas y del proceso de la carga del galeón puede verse en la obra ya clásica de SchURTZ, 1992, pp. 161-184.

4 Aportaciones interesantes a la historia de las mujeres en Filipinas son las realizadas por Marta María Manchado, tanto en relación a la religiosidad y educación femenina como a sus relaciones familiares y estrategias de poder. Véase MANCHADo 1999a, 1999b, 2006, 2008 y 2011.
} 
Mi propósito final va más allá de lo que ofrezco en este artículo. Pretendo reconstruir las redes familiares y de influencia, la vida y el trabajo de estas viudas en un mundo preferentemente masculino. Quisiera rescatarlas del olvido y mostrar la forma como preservaron, e incluso mejoraron, el patrimonio familiar a través de su participación del comercio del galeón.

\section{SITUACIÓN DE LAS VIUDAS EN EL CONTEXTO COLONIAL HISPA- NOAMERICANO (Y FILIPINO)}

El mundo de las viudas en Manila presenta muchos puntos de interés. Algunas mujeres se movían con gran independencia, tanto en la vida social de la ciudad, como en las actividades económicas. Muchas de ellas gozaban de una posición holgada, con una encomienda recibida del difunto marido, cierto patrimonio invertido en casas y obras de arte de origen oriental, además de los derechos de participación en la carga del Galeón de Manila. Si también habían estado casadas con algunos de los primeros pobladores de las islas, un nuevo matrimonio suponía para el varón introducirse en la pequeña aristocracia de la capital y acceder más fácilmente a oficios de prestigio o de autoridad, sobre todo en el ámbito municipal. Era pues bastante normal, en el contexto colonial en general, y en Manila en particular, que las viudas volvieran a contraer segundas nupcias, e incluso que se casaran por tercera $\mathrm{vez}^{5}$.

Una parte importante de sus vidas giraba en torno al Galeón de Manila y la posibilidad de participar en la carga. Lo que en principio se otorgaba como una pensión, un medio de vida que les impidiera caer en una "pobreza vergonzante" -tal y como aparece en los documentos ${ }^{6}$, era para muchas una oportunidad de continuar con el negocio mercantil de sus maridos. Funcionaban, de hecho, como verdaderas comerciantes, cargando un número significativo de piezas y demostrando su solvencia económica. Además, muchas se beneficiaban de las redes familiares que les otorgaban protección a la hora de invertir en este negocio.

Carmen Yuste, por ejemplo, señala que las mujeres en Manila gozaban de una gran libertad de actuación y se desenvolvían con tal autonomía y seguridad, que resultaba extraña, por ejemplo, a los comerciantes mexicanos ${ }^{7}$. A principios del siglo XIX, el historiador Martínez de Zúñiga relataba que las mujeres en Filipinas hablaban con más libertad que en otras tierras. Aunque eso no quería decir -aseguraba- que no fueran recatadas, se quejaba de lo extendido que estaba entre ellas la costumbre de fumar en público con unos cigarros largos y gordos, costumbre que no era mal vista en sociedad ${ }^{8}$.

En cualquier caso, esa mayor libertad en las costumbres era usual en las sociedades coloniales de ultramar, donde la ley no se aplicaba de manera tan estricta como en la metrópoli. Así, por ejemplo, aunque en principio no podían heredar encomiendas,

\footnotetext{
5 Cfr. Muriel, 2002, p. 98.

6 SChurTz, 1992, pp. 167-168.

7 Cfr. Yuste, 2007, pp. 77-78 y 87-88.

8 Cfr. MartíneZ de ZúÑIGA, 1893, pp. 180-181.
} 
de hecho las heredaban ${ }^{9} \mathrm{y}$, en general, como afirma Lavrin, "a pesar de su posición subordinada y su falta general de educación formal las mujeres cuando las circunstancias lo requerían mostraron iniciativa y capacidad para ordenar sus propias vidas sin ayuda del hombre, sobre todo las solteras adultas y las viudas" 10 .

La viudez implicaba derechos y libertades, pero también obligaciones, pues recaía sobre ellas el cuidado, educación y manutención de hijos y nietos ${ }^{11}$. También en el ámbito anglosajón está documentada la gestión temporal de empresas por parte de las mujeres cuando quedaban viudas, ya lo fueran de banqueros, comerciantes y otros miembros de la alta burguesía, como han estudiado Elena Davidoff y Catherine Hall. Según afirman, "de hecho se beneficiaron muchos hombres jóvenes, que al llegar a la edad adulta se encontraban con un patrimonio reunido por su madre (o por su madrastra o por su tía)" 12 .

Como en Filipinas, se puede encontrar en la sociedad de Buenos Aires, durante el siglo XVIII, a mujeres que se hacían cargo de los negocios de sus maridos difuntos, aunque fuera bajo la supervisión de un hijo o un cuñado ${ }^{13}$. Es destacable también la capacidad empresarial de algunas ricas herederas en la ciudad de la Paz en Charcas durante el siglo XVII ${ }^{14}$. Un comportamiento similar ha sido estudiado para las mujeres en Quito entre los siglos XVIII y XIX. La dinámica comercial y económica que desarrollaron tiene similitudes con las de Filipinas que también utilizaron en su provecho la legislación proteccionista sobre la mujer y actuaron con decisión en medio de una sociedad que las consideraba incapaces, demostrando esa ambivalencia entre la "imbecilidad y el coraje" que ha descrito De Borchart en su trabajo sobre la participación femenina en la economía colonial de Quito ${ }^{15}$. De la misma forma, algunos de los casos que he encontrado en la documentación sobre Filipinas demuestran más capacidad comercial y conocimiento en estas materias de las que en principio se podía esperar y un adecuado uso, en su beneficio, de las leyes que las protegían, a la hora de las reclamaciones, peticiones de ayudas económicas, etc.

\section{LAS VIUDAS EN MANILA Y EL COMERCIO DEL GALEÓN}

Era algo estipulado desde los primeros años de vida del Galeón que las viudas recibieran una o dos piezas para cargar en la nao, es decir, que podían cargar en la nao mercancías por valor de 150 a 300 pesos. Aunque esta asignación se consideraba una obra de caridad, no fue así en muchos casos. De hecho, se observan dos tipos de comportamientos. La mayoría de las viudas contaba con esas piezas como un medio de subsistencia, pero algunas las utilizaban para invertir del mismo modo que lo hacían

\footnotetext{
9 LAVRIN, 1984, p. 115.

10 Ibídem, p. 135.

11 Muriel, 2002, p. 96.

12 Davidoff - Hall, 1994, p. 212.

13 Cfr. Socolow, 1978, p. 35. Cfr. Aguirrezabala, 2001 y 2007.

14 Cfr. López Beltrán, 2002, pp. 159-163.

15 Cfr. Borchart de Moreno, 1991.
} 
los comerciantes masculinos. Estos dos modos de utilizar las piezas asignadas se reflejaban, por ejemplo, en la reclamación que se hizo a la autoridad superior en 1705, a propósito de la prohibición de revender las piezas adjudicadas a otros comerciantes. Las viudas -"las pobres viudas", era el término que encabezaba la reclamación- dirigieron una carta al gobernador, señalando lo perjudicial de la medida, tanto "para las que tenían caudales como para las que carecían de ellos porque con la venta de las boletas se alimentaban las que no tenían que cargar y había otras que las compraban para conservar sus caudales y ahora tampoco pueden hacerlo". Afirmaban que, si no se cambiaba esa orden, se verían obligadas a perjurar: "para no caer en la miseria están en grave peligro de perjurar vendiendo la carga que se les da y diciendo que es propio lo que con ella se emplea, en peligro por tanto de ofender a Dios" ${ }^{16}$.

Sugerían, como solución alternativa, que se tasaran las boletas y se diera un tanto por ciento de su valor a quienes las devolvieran a la junta. La resolución del gobernador a favor de esta petición es una muestra del poder que el colectivo de viudas llegó a tener en la sociedad de Manila. A partir de ese mismo año, la Junta de Repartimiento, después de asignar las piezas, determinaría también el tanto por ciento que debía entregarse a quienes las devolvieran. Es interesante destacar que fueron las viudas las que se decidieron a hacer la reclamación al gobierno superior, cuando también había muchos hombres a quienes esa medida perjudicaba.

Por otra parte, el interés de esa carta radica en que revela la existencia de algunas viudas que funcionaban como comerciantes, invirtiendo en la reventa de piezas para adquirir más carga en el galeón, situándose así en el ámbito de los mercaderes empresarios. De hecho, aunque la carta estaba firmada por veintinueve mujeres, ellas mismas aclaraban que lo hacían también en nombre de otras que solicitaban la revisión del reglamento. Todo indicaba, además, que las más interesadas en revocarlo eran las comerciantes porque, cuando finalmente se estableció la tasación de las piezas devueltas, fueron muy pocas -solo seis- las que llegaron a devolver las suyas, mientras que algunas de las firmantes recibieron más en la segunda junta de 1705, reunida para repartir las que se habían devuelto. Algunas de ellas, como Gertrudis de Monterrey, Juana Fernández Vallejo o María Rosa Rayo Doria, recibieron entre una y tres piezas más. Eran mujeres que invertían de una forma importante y continuada desde finales del siglo XVII.

Las dos series de listas de repartimientos de piezas en las que se basa este estudio muestran la proporción de las mujeres comerciantes y la entidad de los negocios que desarrollaron. La primera son las listas recogidas de 1691 a 1701 con ocasión del juicio de residencia del gobernador Fausto Cruzat y Góngora en $1702^{17}$. La segunda relación se recogió en el año 1711. Se encuentra en un largo expediente adjunto a una carta de los regidores al rey, en la que solicitaban la tonelada de privilegio en razón de su cargo, de la que siempre habían disfrutado. Para demostrar esa tradicional concesión, presentaron las juntas de repartimiento de 1705 a 1708. De este modo, he

16 Carta de las viudas de Manila al gobernador. Manila, 20-V-1705. En el expediente del cabildo secular de Manila sobre merced de la tonelada a los regidores, 1705. Archivo General de Indias (en adelante AGI), Filipinas, 187, n. 18, ff. 175-179.

17 Juicio de Residencia contra Fausto Cruzat y Góngora. Manila, 1702. AGI, Escribanía de Cámara, 41 5-A, ff. 22-126v. 
contado con una larga serie de años de 1691 a 1708 que, aunque con algún vacío, permite establecer algunas pautas de comportamiento en las inversiones de las viudas y destacar los negocios de algunas de ellas.

Los datos que esas listas proporcionan, confirman que la participación femenina en el comercio del galeón fue escasa, pero siempre constante, como se refleja en el siguiente gráfico que distingue el reparto de la carga entre hombres y mujeres.

Gráfico 1. Reparto de piezas de la carga del Galeón (1691-1708).

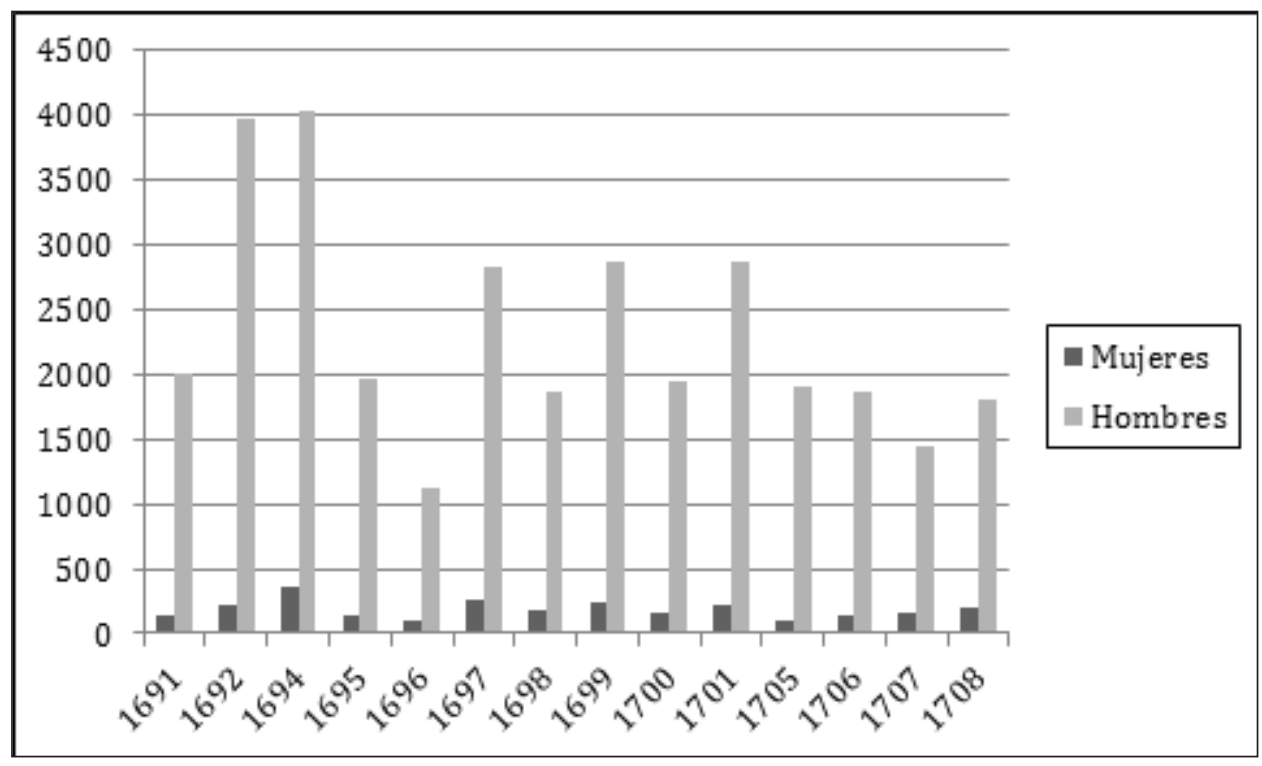

Fuente: Elaboración propia.

Apenas representaban un $8 \%$ de la carga total, aunque aumentó a un $10 \%$ en los dos últimos años, 1707 y 1708. Es interesante observar que, aunque en los últimos años de este período la participación en el comercio sufrió cierto descenso, esto afectó sobre todo a los hombres, mientras que el número de piezas adjudicadas a mujeres aumentó sensiblemente.

Por otra parte, tampoco se puede olvidar que la mayoría de las viudas recibían de una a tres piezas, como muestra la gráfica siguiente. Es lo que propiamente sería una pensión de viudedad. A partir de cuatro piezas puede hablarse ya de mujeres comerciantes que mueven mercancías por valor de 600 pesos en adelante. Un número importante de viudas cargó continuadamente, durante este período, entre cuatro y nueve piezas, por lo que pueden incluirse en el grupo de los medianos comerciantes. Una pequeña minoría recibía entre 10 y 20 piezas. Eran mujeres con una fortuna suficiente como para hacerse cargo de ese número de piezas, lo que suponía mover cantidades entre los 1.500 y 3.000 pesos. Solo en 1694 hay una viuda que recibió 40 piezas, es decir, que cargó mercancías con valor en torno a los 6.000 pesos. De cualquier forma, se trata de un caso aislado, no solo porque Josefa Cortés fue la única viuda que en 
este período recibió una cantidad tan importante, sino también porque parece que únicamente recibió piezas ese año. O bien volvió a casarse al año siguiente o falleció, porque su nombre dejó de aparecer en las listas de repartimiento.

Gráfico 2. Número de piezas repartidas a las viudas.

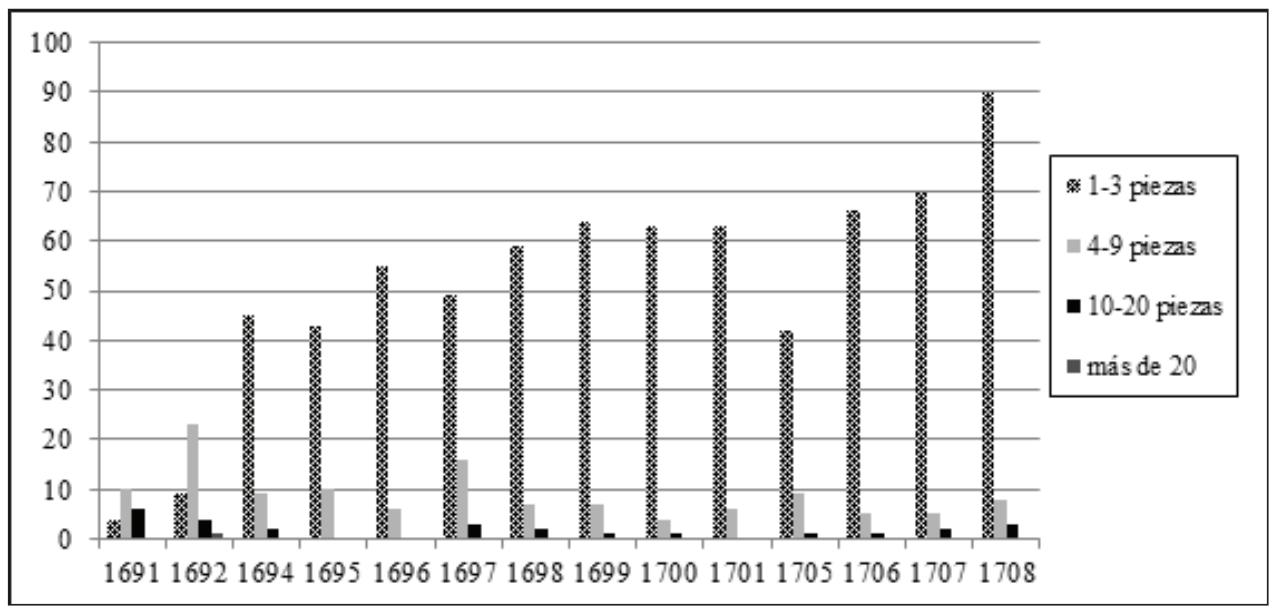

Fuente: Elaboración propia.

Merece la pena destacar el volumen comercial desarrollado por algunas viudas. En parte porque su participación en la carga del galeón fue constante a lo largo de estos años, pero también porque recibían un número importante de piezas. Son los nombres que he seleccionado en la siguiente tabla. La mayoría empezó a cargar entre cuatro y seis piezas cada año, aunque las cantidades fueron disminuyendo progresivamente. Es el caso de Gertrudis de Monterrey, María Espinosa de los Monteros, Felipa Gómez de Baeza o Margarita de Alarcón.

Tabla 1. Número de piezas asignadas a principales viudas comerciantes.

\begin{tabular}{|l|c|c|c|c|c|c|c|c|c|c|c|c|c|c|}
\hline $\begin{array}{l}\text { CO- } \\
\text { MER- } \\
\text { CIAN- } \\
\text { TES }\end{array}$ & 1691 & 1692 & 1694 & 1695 & 1696 & 1697 & 1698 & 1699 & 1700 & 1701 & 1705 & 1706 & 1707 & 1708 \\
\hline $\begin{array}{l}\text { Marga- } \\
\text { rita de } \\
\text { Alarcón }\end{array}$ & 4 & & 8 & 3 & 1 & 4 & 2 & 3 & & & & 3 & 3 & 3 \\
\hline $\begin{array}{l}\text { Rosa } \\
\text { Rayo } \\
\text { Doria }\end{array}$ & & & & & 8 & 12 & 10 & & & & 16 & 16 & 14 & 12 \\
\hline $\begin{array}{l}\text { Lucía de } \\
\text { Silva }\end{array}$ & 6 & 8 & & 2 & 1 & 4 & 2 & 4 & 2 & 3 & 8 & 6 & 9 & \\
\hline $\begin{array}{l}\text { María de } \\
\text { Escaño }\end{array}$ & & & & & & & & & & & & & 14 & 12 \\
\hline
\end{tabular}




\begin{tabular}{|c|c|c|c|c|c|c|c|c|c|c|c|c|c|c|}
\hline $\begin{array}{l}\text { Manuela } \\
\text { de la } \\
\text { Vega }\end{array}$ & & & & & 4 & 10 & 6 & 6 & & & & & & \\
\hline $\begin{array}{l}\text { Gertru- } \\
\text { dis de } \\
\text { Monte- } \\
\text { rrey } \\
\end{array}$ & 4 & 6 & 6 & 3 & 1 & 3 & 2 & 3 & 2 & 3 & 2 & 2 & 2 & 3 \\
\hline $\begin{array}{l}\text { Mar- } \\
\text { garita } \\
\text { Verdugo }\end{array}$ & 4 & 6 & 4 & 2 & 1 & 3 & 2 & 3 & 2 & 3 & 1 & 1 & 1 & 2 \\
\hline $\begin{array}{l}\text { Felipa } \\
\text { Gómez } \\
\text { de la } \\
\text { Cueva }\end{array}$ & & 6 & 4 & 2 & 1 & 3 & 2 & 3 & 2 & 3 & 1 & 1 & 1 & 1 \\
\hline $\begin{array}{l}\text { Ana } \\
\text { Rayo } \\
\text { Doria }\end{array}$ & & & & & & & & & & & 2 & 3 & 4 & 3 \\
\hline $\begin{array}{l}\text { María } \\
\text { Espinosa } \\
\text { de los } \\
\text { Monte- } \\
\text { ros }\end{array}$ & 4 & 15 & 10 & 4 & 4 & 8 & 4 & 6 & 4 & 8 & 2,5 & 5 & 2,5 & 3 \\
\hline $\begin{array}{l}\text { Leonor } \\
\text { de Fi- } \\
\text { gueroa }\end{array}$ & & & 4 & 2 & 1 & 3 & 2 & 3 & 2 & 3 & 2 & 2 & 2 & 1 \\
\hline
\end{tabular}

Fuente: Elaboración propia.

No se limitaron a recibir los beneficios de este comercio. Margarita de Alarcón, por ejemplo, compró en 1708, a Francisco Atienza Ibáñez, dieciséis tiendas de madera, junto con una casa de piedra y un solar situados en la traza de la ciudad, con la idea de ponerlas en alquiler y percibir una renta ${ }^{18}$. Poseía también una casa en Cavite y otra en Binondo. Sobre esta última había impuesto un censo para la fundación de una capellanía de misas ${ }^{19}$. No se conformó con el comercio legal. En 1687 aparece como una de las personas implicadas en el caso de las mercancías embarcadas fuera de registro en el galeón Santo Niño ${ }^{20}$. Es curioso observar que, además de Margarita de Alarcón, había otras seis mujeres implicadas en este negocio, lo que es una muestra de la integración que podían llegar a tener en estas redes comerciales.

El carácter resolutivo de Margarita se manifestó en la resistencia a pagar la multa que se le había impuesto por el fraude cometido. Ella argumentaba que más bien debería pagarle la Real Hacienda todo lo que debía a su difunto marido, el almirante Leandro Coello, por sueldos atrasados. A causa de esos retrasos estaba pobre -decía-

18 Escritura de venta de tiendas a favor de Margarita de Alarcón. Manila, 23-XI-1708. Archdiocesan Archives of Manila (en adelante AAM), 4.A.1, carpeta 3, ff. 51-55.

19 Libro de cuentas de cargo y data perteneciente a la capellanía de Margarita de Alarcón, Manila, 5-IV1762, AAM, legajo 11.B.5, carpeta 1. Jon Mesquida en su estudio sobre las capellanías en Manila refleja que la mayor parte de los fundadores de capellanías eran gente adinerada. MesQUIDA, 2010, p. 475.

20 La historia de este galeón ha sido estudiada de forma completa y sobre todo este de 1687, que fue su último viaje por VARELA, 2013, pp. 239-246. 
y había tenido que vender todos los bienes de su marido en pública subasta para pagar las costas de un juicio ${ }^{21}$. Finalmente tuvo que pagar la multa exigida sin que repercutiera en el volumen de sus negocios ${ }^{22}$. Es difícil, en cualquier caso, creer que viviera en una situación de pobreza -como ella afirmaba-, si se tiene en cuenta que, al menos de 1691 a 1708, cargaba en el galeón una media de cuatro piezas cada año, es decir, unos quinientos pesos aproximadamente.

Otras viudas de las que tenemos más datos son, por ejemplo, Lucía de Silva, María de Escaño y Córdoba, María Manuela de la Vega y María Rosa Rayo Doria. Cada una de ellas cargaba mercancías por valor de más de mil pesos. Lucía y María Rosa recibieron piezas en las segundas adjudicaciones, señal de su reputación como comerciantes.

También es cierto que el volumen que manejaban estaba por debajo de lo que cargaban grandes mercaderes como Tomás de Endaya, Francisco Atienza Ibáñez o José de Oscorta -y algunos más que he entresacado en la siguiente tabla-, quienes solían invertir una media de nueve mil pesos cada año.

Tabla 2. Número de piezas asignadas a los principales comerciantes

\begin{tabular}{|l|c|c|c|c|c|c|c|c|c|c|c|c|c|c|}
\hline $\begin{array}{l}\text { COMER- } \\
\text { CIAN- } \\
\text { TES }\end{array}$ & 1691 & 1692 & 1694 & 1695 & 1696 & 1697 & 1698 & 1699 & 1700 & 1701 & 1705 & 1706 & 1707 & 1708 \\
\hline $\begin{array}{l}\text { Tomás de } \\
\text { Endaya }\end{array}$ & 60 & 80 & 136 & 85 & 58 & 100 & 76 & 146 & 92 & 116 & 72 & 60 & 50 & 83 \\
\hline $\begin{array}{l}\text { Bernar- } \\
\text { do de } \\
\text { Endaya }\end{array}$ & 40 & 70 & 50 & & 30 & 20 & 40 & 96 & 74 & & -- & -- & -- & -- \\
\hline $\begin{array}{l}\text { José de } \\
\text { Oscorta }\end{array}$ & 30 & 100 & 50 & 36 & 50 & & 40 & 75 & 40 & 116 & 82 & 66 & 50 & 56 \\
\hline $\begin{array}{l}\text { Fran- } \\
\text { cisco de } \\
\text { Atienza }\end{array}$ & 50 & 80 & 90 & 56 & 44 & 80 & 50 & 76 & 50 & 76 & 77 & 85 & 80 & 67 \\
\hline $\begin{array}{l}\text { Francisco } \\
\text { de Moya }\end{array}$ & 80 & 90 & 71 & 54 & 80 & 50 & 76 & 50 & 76 & 72 & 60 & -- & -- \\
\hline $\begin{array}{l}\text { Marcos } \\
\text { Quintero }\end{array}$ & 120 & 90 & 56 & 44 & 80 & 50 & 76 & 50 & 76 & & & & \\
\hline $\begin{array}{l}\text { Pedro de } \\
\text { Oriosolo }\end{array}$ & 50 & 40 & 50 & 25 & -- & & & & & & & & & \\
\hline $\begin{array}{l}\text { Miguel } \\
\text { de Elo- } \\
\text { rriaga }\end{array}$ & & & & & & & 6 & & & & 53 & 73 & 54 & 40 \\
\hline
\end{tabular}

Fuente: Elaboración propia.

21 Certificación del pago de la fianza de Margarita de Alarcón. Cavite, 15-IV-1699. AGI, Filipinas, 68, ff. 47-49 y ff. 109-110r.

22 Cfr. listas de repartimientos de 1691-1701. Juicio de Residencia contra Fausto Cruzat y Góngora. Manila, 1702. AGI, Escribanía de Cámara, 415-A, ff. 22-126v; listas de repartimiento de 1705-1708. Expediente anexo a la carta al de la ciudad de Manila sobre merced de la tonelada a los regidores. Manila, 5-VII-1711. AGI, Filipinas, 187, n. 18. 
Pero si tenemos en cuenta que la gran mayoría de los vecinos de Manila recibía solo una o dos piezas, estas mujeres se encuentran entre el número de los medianos comerciantes con una respetable fortuna.

Claramente se beneficiaban también del hecho de pertenecer a familias poderosas o influyentes en la ciudad, bien por lazos de matrimonio o de parentesco. María de Escaño, por ejemplo, que llegó a las islas en 1672 con siete años, era la hija de un antiguo oidor de la Audiencia de Manila y viuda de un destacado comerciante de las islas, Francisco de Moya y Torres, regidor de Manila ${ }^{23}$; Lucía de Silva era nieta de un antiguo gobernador, Fernando de Silva, que había desarrollado una importante política matrimonial para afianzar su familia en las islas ${ }^{24}$.

Manuela de la Vega era viuda del almirante Domingo de Lizarralde, con quien había estado casada de 1686 a 1694, año en que murió su marido. Los padrinos de la boda fueron Francisco de Atienza y su mujer, señal de las buenas relaciones que tenían los contrayentes ${ }^{25}$. Atienza Ibáñez era regidor de la ciudad y un destacado comerciante, un personaje poderoso e influyente en la ciudad ${ }^{26}$.

Domingo de Lizarralde había estado implicado en la introducción de mercancías fuera de registro en el galeón Santo Niño. Quizá su poderoso padrino y vecino, Atienza Ibáñez, le había facilitado la participación en esta operación, pues también era uno de los acusados junto con otros importantes comerciantes, como Tomás de Endaya.

El caso es que, cuando la justicia tomó cartas en el asunto y exigió el pago de una multa a los culpables, ya en 1700, tanto Domingo como María Manuela habían fallecido. Nicolás de la Vega, hermano de esta, como albacea testamentario de los bienes de Manuela, tuvo que afrontar un largo proceso contra la Real Hacienda para evitar que el pago de la multa impuesta a Domingo de Lizarralde recayera sobre la herencia, que correspondía a los hijos menores del matrimonio. La documentación generada por este proceso -Nicolás tenía que demostrar que los bienes de María Manuela procedían de su dote y que no había heredado nada de su marido- aporta datos interesantes sobre la posición económica de esta mujer y la actividad comercial que desarrolló ${ }^{27}$.

María Manuela de la Vega tenía una holgada posición económica. Había aportado al matrimonio una dote de unos 7.000 pesos, que incluía una casa en la traza de la ciudad -donde vivieron los esposos-, un número importante de joyas, dos esclavos más ropa de casa y menaje valorados en mil pesos ${ }^{28}$. Parte del dinero que su madre, Águeda de los Reyes, había reservado para la dote se había invertido anteriormente en el comercio del Galeón. Cuando María Manuela enviudó, quedó como albacea

23 Francisco de Moya debió casarse en segundas nupcias con María de Escaño. Petición de licencia al rey de Fernando Escaño y Córdoba para ir a Filipinas con su mujer e hijos por haber sido nombrado oidor. Sevilla, 1760. AGI, Filipinas, 23, r. 11, n. 34; Relación de méritos y servicios de Francisco de Moya y Torres. Manila, 29-IX-1989. AGI, Filipinas, 118, n. 3.

24 Cfr. Alva, 1997, Apéndice, cuadro genealógico 2.

25 Certificación de matrimonio. Manila, 17-XI-1686. AGI, Filipinas, 68, n. 1, ff. 148-149v.

26 Cfr. Alva, 2013, pp. 237-239.

27 Autos para el cobro de la fianza del sargento mayor Domingo de Lizarralde. En Testimonio de los autos hechos sobre la arribada del galeón Santo Niño y Nuestra Señora de Guía. Manila, 1688-1701. AGI, Filipinas, 68, ff. 141-377r.

28 Carta de dote de María Manuela de la Vega. Manila, 9-V-1687. AGI, Filipinas, 68, ff. 150-153. 
de los bienes de su marido, lo que la obligó a emprender una serie de acciones para cobrar diversas deudas de personas repartidas entre Filipinas y Nueva España. Las cartas de sus corresponsales en México, a los que Manuela había otorgado poderes para el cobro de las cantidades que se debían a su difunto marido ${ }^{29}$, reflejan la actitud de una mujer decidida, empeñada en recibir las cantidades adeudadas. Además, esas cartas incluyen el intercambio y las relaciones comerciales entablados con sus representantes en México. María Manuela les enviaba cacao, piezas de marfil, sedas y mantas de la tierra al tiempo que les solicitaba libros, pinturas y piezas de plata labra$\mathrm{da}^{30}$. Emprendió también dos demandas en Manila. La primera, contra Fermín de la Ortiga, para que pagara un sampán que había comprado a su marido ${ }^{31}$; y la segunda, contra el alférez Cristóbal Basurto, por una deuda que no se determinaba a pagar ${ }^{32}$.

Aunque se quejaba de que su marido no le había dejado más que deudas imposibles de cobrar y de que la mayor parte de la herencia se había ido con los gastos de funeral, costas de juicios, pagos a escribanos, etc., lo cierto es que su patrimonio debía ser importante, pues como viuda embarcó entre 6 y 10 piezas de 1696 a 1699 (cfr. Tabla 1) ${ }^{33}$. María Manuela de la Vega era, por tanto, una mujer adinerada que supo manejarse con soltura, utilizando los instrumentos legales necesarios para conseguir sus derechos.

El caso más ilustrativo es el de María Rosa Rayo Doria, no solo por el número importante de piezas que embarcaba, sino porque se benefició de una red de relaciones familiares y comerciales de las que supo sacar provecho. Es por esto por lo que le dedicaré una atención especial.

\section{MARÍA ROSA RAYO DORIA: VIUDEDAD Y REDES FAMILIARES}

María Rosa había nacido en Manila en el seno de una familia que llevaba establecida en la ciudad desde mediados del siglo XVII. Su padre, Sebastián Rayo Doria, fue un controvertido personaje, mexicano de origen genovés, implicado en la prisión del gobernador Diego Salcedo. La trayectoria de Sebastián es ejemplo de una bien pensada estrategia matrimonial para establecer lazos con las familias influyentes de Manila. Un primer matrimonio con María Balmaseda lo entroncó con una de las familias más antiguas de Manila, los Ezquerra ${ }^{34}$. Al morir su mujer, contrajo un nuevo matrimonio con Ana Pestaño. Este enlace le introdujo en los circuitos comerciales del Galeón y le abrió las puertas para acceder al cabildo secular de Manila ${ }^{35}$. En 1676 se convirtió en escribano mayor de cabildo, por la renuncia que había hecho en él su cuñado, Fran-

29 Otorgamiento de poder universal. Manila, 24-V-1696 y 18-IV-1698. AGI, Filipinas, 68, ff. 268-273.

30 Cartas de Juan de Cabueñaz, Diego Manuel Carballido y Miguel Ortuño de Carriedo a María Manuela de la Vega. México, 5-III-1697, 12-III-1697, 12-III-1698, 1-III-1699 y 10-III-1699. AGI, Filipinas, 68, ff. 278r-294r.

31 Demanda contra Fermín de la Ortiga. Manila, 24-X-1698. AGI, Filipinas, 69, ff. 275r-277.

32 Demanda contra Cristóbal Basurto., Manila, 8-X-1695. AGI, Filipinas, 68, ff. 308-313.

33 Listas de repartimiento de 1691-1701. Juicio de Residencia contra Fausto Cruzat y Góngora. Manila, 1702. AGI, Escribanía de Cámara, 415-A, ff. 22r-126.

34 Alva, 1997, Apéndice, cuadro genealógico 15.

35 Ibídem, cuadro genealógico 8. 
cisco Pestaño ${ }^{36}$. La relación con los Pestaño fue importante, también por introducir a los Rayo Doria en la órbita de Tomás de Endaya y su familia, quien además de ser un poderoso comerciante, era hombre de confianza de los gobernadores y tenía conexiones importantes en los instrumentos del reparto de mercancías en el galeón. También se emparentó con otro destacado comerciante, Francisco de Moya y Torres, que estaba casado con una hermana de Ana, Bernarda ${ }^{37}$. La relación entre ambos debió ser tan estrecha, que fue Francisco quien se hizo cargo como albacea de los bienes de Ana, cuando esta falleció, para que la herencia pasara a los hijos y no se viera afectada por los problemas que Sebastián Rayo Doria tuvo con la Real Caja ${ }^{38}$.

De su matrimonio con Ana Pestaño nacieron sus hijos Francisco, Bartolomé, María Rosa y Ana. Los dos varones hicieron carrera eclesiástica. Francisco llegó a ser arcediano de la catedral de Manila y procurador de la Sagrada Congregación de Propaganda Fide ${ }^{39}$. Bartolomé fue también canónigo de la catedral ${ }^{40}$.

María Rosa había contraído matrimonio con Pedro de Oriosolo ${ }^{41}$, general del galeón en 1689 y castellano del puerto de Cavite desde $1690^{42}$. Es bastante posible que en esos años de matrimonio aprendiera del funcionamiento de la carga del Galeón, ya que precisamente desde Cavite se controlaba todo lo relativo al arqueamiento y preparación de las naves. De hecho, su marido era también un importante comerciante, a juzgar por su participación en el Galeón de 1691 a 1695, años en los que carga de 40 a 50 piezas anuales. En 1696 María Rosa debía ya de haber enviudado, pues aparece en las listas de repartimiento de 1696 a 1698, cargando un número importante de piezas (cfr. Tabla 1). Es de hecho la viuda que más piezas embarcó en esos años.

Un nuevo matrimonio, esta vez con Bernardo de Endaya, la situó en el centro neurálgico de las redes comerciales. El maestre de campo Tomás de Endaya, su cuñado, era el hombre de confianza del gobernador Fausto Cruzat, y había sido regidor de la

36 Confirmación del oficio de escribano de cabildo a Sebastián Rayo Doria. Madrid, 19-VII-1678. AGI, Filipinas, 46, n. 62.

37 Bernarda era la primera mujer de Francisco de Moya y Torres. Al quedar viudo, volvió a casarse con María de Escaño, como se ha visto.

38 Sebastián Rayo Doria estuvo implicado, siendo alcalde ordinario de Manila, en los hechos que llevaron a la prisión del gobernador Diego Salcedo. Tenía además pendiente algunas causas con la Real Hacienda por el desfase en las cuentas cuando fue alcalde mayor de Tondo. Gracias a los matrimonios consiguió estar muy bien relacionado, llegando a ser hombre de confianza de gobernadores como Gabriel de Curucelaegui y Manuel de León. El declive de su carrera comenzó en 1680 cuando fue nombrado gobernador de las Islas Marianas por el gobernador Juan de Vargas, un nombramiento que Rayo Doria interpretó como un destierro. Carta al rey de Sebastián Rayo Doria. Manila, 6-VI-1682. AGI, Filipinas, 44, n. 17. Algunos de sus contemporáneos, como el oidor Calderón y Serrano, no se explicaban la facilidad con que había ascendido en la escala social considerándolo "de arte diabólico, de palabras blandas, de trato doble". Carta al rey del oidor Francisco Calderón y Serrano. Manila, 8-VI-1678. AGI, Filipinas, 44, n. 3.

39 Carta al rey de Fausto Cruzat y Góngora. Manila, 25-V-1701. AGI, Filipinas, 124, n. 8; Promoción de Francisco Rayo Doria a chantre de la catedral de Manila. Madrid, 8-IV-1720.

40 Carta al rey de Domingo de Zabalburu sobre canonjía magistral. Manila, 14-VI-1707. AGI, Filipinas, 129, n. 9; Promoción de Bartolomé Rayo Doria a canónigo magistral de la catedral de Manila. El Pardo, 24VIII-1714. AGI, Filipinas, 1005, n. 115.

41 Manchado López, 2014, p. 9.

42 Real cédula al virrey de Nueva España sobre sueldo de Pedro de Oriosolo. Madrid, 7-III-1697. AGI, Filipinas, 341, n. 8, ff. 120-121r; Relación de méritos y servicios de Pedro Oriosolo, Manila, 29 de enero de 1690. AGI, Indiferente General, 132, n. 97. 
ciudad y alcalde ordinario en $1679^{43}$. Durante los años de mandato de Cruzat fue uno de los cargadores de la nao, desde 1693 hasta 1701, excepto en 1697, en que la tarea recayó sobre su hermano Bernardo. Un cargador gozaba del privilegio de cargar más piezas, además de las que le correspondía por ser vecino. El volumen de comercio que ambos hermanos manejaban estaba muy por encima del correspondiente al resto de los vecinos (cfr. Tabla 2).

María Rosa volvió a enviudar en 1702. Su marido murió en la travesía de vuelta de la nao que mandaba como general. A partir de ese año, volvió a aparecer en las listas de repartimiento con un número importante de piezas, entre 12 y 16 (cfr. Tabla 1). No solo se hizo cargo de las cantidades que se le adjudicaron en esos años, sino que recibió alguna pieza más en los segundos repartos ${ }^{44}$. Su participación era bastante superior a la del resto de las viudas, con excepción de María Escaño y Lucía de Silva. Una muestra más de la influencia que la red familiar Endaya-Rayo tenía en la carga del Galeón es el hecho de que un yerno de María Rosa, Miguel de Elorriaga, comenzara a cargar a partir de 1705 más de cincuenta piezas al año, cuando en 1698 solo había conseguido que le adjudicaran seis (cfr. Tabla 2).

El matrimonio de Miguel con una de las hijas de María Rosa Rayo y Bernardo de Endaya era un caso más de la facilidad con que se podía ascender en la escala social de Manila si se encontraba la esposa adecuada. De piloto de nao, Miguel pasó a ser escribano de cabildo y compró el oficio de regidor en 1710. Un año antes, se había destacado por dirigir una expedición a las islas Palaos. En 1720, ocupaba la importante plaza de castellano del puerto de Cavite ${ }^{45}$. Pero Miguel de Elorriaga se convirtió sobre todo en un destacado comerciante que manejaba un importante volumen de comercio, a juzgar por los registros de la carga del galeón. Es posible también que trabajara junto con su suegra, como era usual en casos semejantes.

Una manifestación de la determinación de María Rosa fue también la constancia con que persiguió que la Corona declarara inocente a su difunto marido de una acusación que hacía peligrar el patrimonio familiar. Bernardo de Endaya había sido condenado por la supuesta venta de la posaverga de un barco que había gobernado como general. Al no haber ingresado en la caja real el resultado de esa venta, unos 1.800 pesos, se le impuso una multa. Como había fallecido cuando llegó la resolución, debía aplicarse sobre los bienes de sus herederos. María Rosa fue apelando a los distintos tribunales hasta conseguir demostrar la inocencia de su marido. Para ello tuvo que buscar a los diversos testigos que verificaran que Bernardo no había vendido el mástil, sino que lo había regalado al capitán de un barco que navegaba rumbo a Perú, por estar ya inservible. No había habido fraude y los bienes de sus hijos quedaban libres de esa carga ${ }^{46}$.

Una hermana de María Rosa, Ana Rayo, aparece también en las listas de repartimiento con un volumen de comercio más modesto. Las asignaciones que recibía

43 Alva, 2013, pp. 239-242.

44 Cfr. las juntas de repartimientos de los años 1705-1708 en el expediente anexo a la carta al de la ciudad de Manila sobre merced de la tonelada a los regidores. Manila, 5-VII-1711. AGI, Filipinas, 187, n. 18.

45 Manchado LóPez, 2011, p. 419, nota 15, recoge una breve semblanza de este personaje que llegó a convertirse en un destacado prohombre de la ciudad de Manila.

46 Carta al rey del conde de Lizárraga. Manila, 27-VII-1713. AGI, Filipinas, 168, n. 8. 
fueron aumentando cada año desde los 300 pesos en 1705 a los 530 pesos en 1708 . Es, además, una de las viudas que se presentó a las segundas juntas de repartimiento, para recibir alguna de las piezas que otros vecinos habían devuelto. Su actividad comercial no se redujo a la carga del Galeón de Manila. En 1703, había entregado una cantidad importante de pesos al capitán Pedro de Viñales, que marchaba a Bengala para comprar telas y especias. El promotor de este negocio era un hombre poderoso, Tomás de Endaya, cuñado de su hermana. Las mercancías de este barco tendrían una complicada historia, pues los comerciantes intentaron reducir los derechos de almojarifazgo falseando las facturas o poniéndolas a nombre de otros vecinos. Ana Rayo las puso a nombre de uno de los oficiales que iba en el barco, Antonio Basarte, y se encontró envuelta en un problema legal, al morir Basarte sin haber repartido las telas. Pero no tuvo ninguna duda en hacer valer sus derechos y reclamar los bienes que le pertenecían, aunque estuvieran a nombre de Basarte ${ }^{47}$.

La influencia de esta gran familia se prolongó a través de sus descendientes a lo largo del siglo XVIII. Una de las nietas de María Rosa, Ana de Elorriaga y Endaya, casada con el general Diego Zamudio, ya había enviudado en 1748. En 1752 volvió a casarse, esta vez con Agustín Pedro de Aguirre ${ }^{48}$. A mediados del siglo XVIII, Ana de Elorriaga y Endaya contrataba y cargaba mercancías en el galeón, mostrando un comportamiento independiente, aun a costa de la opinión popular. No se conformó con estos beneficios, sino que supo aprovecharlos para ampliar sus propiedades. En 1751 , poseía ya una casa principal en Manila. Invirtió sus beneficios comerciales en la compra de tierras en el poblado de Santa Ana, cerca de la ciudad, donde las familias adineradas solían tener una casa de verano. Allí se hizo construir una morada, además de otras dos que ya poseía extramuros de la ciudad. En 1766, estaba de nuevo viuda, como consta en las escrituras de otorgamiento de poder universales para que los nombrados por ella llevaran sus asuntos en México, en España y en "los reinos de Europa", señal de la extensión que tenían sus negocios ${ }^{49}$.

También sus elecciones personales mostraban una fuerte personalidad y una gran libertad de actuación, en contra incluso de las costumbres y moralidad de la época. De hecho, en el ínterin entre sus dos matrimonios mantuvo una relación amorosa con un dominico, fray Juan de la Cruz, con el que el que llegó a tener un hijo. Ni amenazas ni súplicas de familiares le hicieron cambiar de opinión. Precisamente la nueva casa que se construyó extramuros de la ciudad cumplía el objetivo de facilitar los en-

47 Gabriel de Istúriz, apoderado de los herederos de Fausto Cruzat y Góngora, Gobernador de las Islas Filipinas, y Tomás de Endaya con Gaspar Sánchez Bernardo de Quirós, alguacil mayor de Manila, sobre paga de cantidad de pesos. Fenecido en 1716. Pleitos de la Audiencia de Filipinas, 1709. AGI, Escribanía, de Cámara 405A; Carta al rey de Domingo de Zabalburu sobre derechos del bajel de Bengala. Manila, 5 -VI-1703. AGI, Filipinas, 127, n. 17.

48 Información matrimonial, Manila, 11 de enero de 1752. AAM, legajo 14.A.1, carpeta 6, ff. 210-213.

49 Poder especial para pleitos otorgado por Ana de Elorriaga y Endaya. Manila, 20-II-1766. National Archives of the Philippines (En adelante NAP), Protocolos Manila, SDS, 19771. fol. 2r; Poder general para todos los efectos en el reino de Nueva España otorgado por Ana de Elorriaga y Endaya. Manila, 23-VII-1766. NAP, Protocolos Manila, SDS, 19771, ff. 57r-58r; Poder general para la Real Corte y Villa de Madrid otorgado por Ana de Elorriaga y Endaya. Manila, 24-VII-1766. NAP, Protocolos Manila, SDS, 19771, ff. 58r-59r. 
cuentros con su amante ${ }^{50}$. Esta relación no le impidió contraer un nuevo matrimonio cuando ella lo consideró conveniente. Un ejemplo, tal vez extremo, de la libertad que una mujer viuda podía gozar en Filipinas.

\section{CONCLUSIONES}

La estructura del comercio en Manila, centrada en la línea del Galeón de Manila, con su particular sistema de reparto de piezas entre los vecinos, permitió la participación destacada de algunas viudas. Aunque, como se ha visto, la mayoría de ellas recibían una o dos piezas como pensión, nunca dejó de haber mujeres que trabajaban como comerciantes independientes. Si bien su nivel económico no podía igualarse a las grandes fortunas de la ciudad, desde luego no eran tampoco "pobres viudas".

Más que continuar con el negocio de sus maridos, parece más bien que aprovecharon la experiencia adquirida junto a ellos para invertir su propia fortuna. También es cierto que, al menos para los casos estudiados, les resultó de ayuda sus relaciones familiares con importantes comerciantes de Manila. No se limitaron a trabajar en esta línea comercial, sino que se introdujeron en el comercio ilegal o diversificaron sus fortunas invirtiendo en la compra de casas o tiendas, a veces para ponerlas en alquiler.

Este primer acercamiento al mundo de las viudas en la Filipinas colonial es un punto de partida para seguir estudiando el papel de las mujeres en el comercio del Galeón. La documentación demuestra que su participación fue más importante de lo que a primera vista pudiera parecer.

\section{REFERENCIAS BIBLIOGRÁFICAS}

Aguirrezabala, Marcela

2001 "Mujeres casadas en los negocios y el comercio ultramarino entre el Río de la Plata y la Península en el siglo XVIII". Anuario de Estudios Americanos. Sevilla, nº 58/1, pp. 111-133.

2007 “Les dones del comerç ultramarí. Riu de la Plata, 1776-1810”. Recerques. Barcelona, $\mathrm{n}^{\mathrm{o}} 56, \mathrm{pp} .131-164$.

Alva, Inmaculada

1997 Vida municipal en Manila (siglos XVI y XVII). Córdoba. Servicio de Publicaciones de la Universidad de Córdoba-Ministerio de Asuntos Exteriores.

2013 "Redes familiares y relaciones comerciales en Manila: Francisco de Atienza Ibáñez y Tomás de Endaya”. En CAVA Mesa (ed.), América en la memoria: conmemoraciones y reencuentros, I. Bilbao. Asociación Española de Americanistas - Universidad de Deusto, pp. 235-244.

2014 "Manila y sus arrabales: un lugar de encuentro entre culturas (siglos XVI-XVIII)". En Manchado López - LuQue Talaván (coords.), Un Mar de Islas, un Mar de Gen-

50 Carta de Pedro Martínez de Arizala, Manila, 21 de julio de 1752. AGI, Filipinas, 292, n. 46. La carta recoge las diligencias para averiguar la verdad de la acusación hecha por Clara de Viscarra, pariente de Ana de Elorriaga, para que se trasladara al dominico a un lugar alejado de Manila. 
tes. Población y diversidad en las Islas Filipinas. Córdoba. Servicio de Publicaciones de la Universidad de Córdoba, pp. 207-221.

Bernabeu Albert, Salvador - Martínez-Shaw, Carlos

2013 Un océano de seda y plata: el universo económico del Galeón de Manila. Sevilla. CSIC.

Borchart De Moreno, Christiana

1991 "La imbecilidad y el coraje. La participación femenina en la economía colonial (Quito, 1780-1830)". Revista Complutense de Historia de América. Madrid, n 17, pp. 167-182.

DavidofF, Elena - HaLl, Catherine

1994 Fortunas familiares. Madrid. Cátedra.

García-ABasolo, Antonio

2011 "Filipinas, una frontera más allá de la frontera". En Manchado LóPEZ - LuQuE Talaván (coords.), Fronteras del mundo hispánico: Filipinas en el contexto de las regiones liminares novohispanas. Córdoba. Servicio de Publicaciones de la Universidad de Córdoba, pp. 78-87.

LAVRÍN, Asunción

1984 "La mujer en la sociedad colonial hispanoamericana". En Bethell (ed.), Historia de América Latina, tomo 4. Barcelona. Crítica, pp. 109-133.

LóPEZ BELTRÁN, Clara

2002 "Empresarias y herederas: viudas de la élite de la ciudad de La Paz en Charcas, siglo XVII". En Ramos Medina, Viudas en la historia. México. Centro de Estudios de Historia de México - Condumex, pp. 147-163.

Manchado LóPEz, Marta $\mathrm{M}^{\mathrm{a}}$

1999a "El proyecto de convento para mestizas de Santa Rosa de Lima, en Filipinas". Anuario de Estudios Americanos. Sevilla, no $56 / 2$ pp. 488-512

1999 b "Religiosidad femenina y educación de la mujer indígena en Filipinas: el beateriocolegio de la Madre Paula de la Santísima Trinidad". Revista de Indias. Madrid, n ${ }^{\circ}$ 59/215, pp. 171-202.

2006a "Adulterio y relaciones de poder en la Manila del siglo XVII", en Sánchez - Provencio (coords.), El Mediterráneo y América, vol. 1. Murcia. Editora Regional de Murcia, pp. 387-403.

2006b "Poder y redes de influencia: las trayectorias de una familia española en Filipinas (1596-1650)". Revista de Indias. Madrid, no 66/238, pp. 629-658

2008 "Familia y estrategias matrimoniales en Manila a principios del siglo XVII: el caso del oidor Antonio Ribera Maldonado", en UsunáRIZ - GARCía BoURRELLIER (coords.), Padres e hijos en España y en el mundo hispánico: siglos XVI y XVII. Madrid, Visor, pp. $125-158$

2011 "Estrategias familiares en una sociedad de frontera: Manila (1571-1604)", en CoNTRERAS (coord.), Familias, poderes, instituciones y conflictos. Murcia, Universidad de Murcia, pp. 79-82

2011 "Desamparo en que con la vida, se pierde el alma: las controversias en torno a la obra pía del Abad Sidoti para la recogida de niños chinos abandonados (Filipinas, 1705-1740)". Revista de Indias. Madrid, nº 71/252, pp. 415-448. doi:10.3989/revindias.2011.014.

2014 "Ley, transgresión y parcialidades en Manila en la primera mitad del siglo XVIII. La boda secreta del fiscal Cristóbal Pérez de Arroyo". Revista Hispanoamericana. 
Publicación digital de la Real Academia Hispano Americana de Ciencias, Artes y Letras. Cádiz, nº 4, pp. 1-25.

MARTíneZ De ZúÑIGA, Joaquín.

1893 Estadismo de las Islas Filipinas o mis viajes por este país, I, Madrid.

Mesquida, Jon

2010 "La población de Manila y las capellanías de misas de españoles". Revista de Indias. Madrid, vol. LXX, nº 249, pp. 469-500. doi:10.3989/revindias.2010.015.

MurIEL, Josefina

2002 "Las viudas en el desarrollo de la vida novohispana". En Ramos (dir.), Viudas en la historia. México. Centro de Estudios de Historia de México, pp. 93-111.

Ramos, Manuel

2002 Las viudas en la historia. México. Centro de Estudios de Historia de México.

SCHURTz, William L.

1992 El Galeón de Manila. Madrid. Ediciones de Cultura Hispánica.

Socolow, Susan M.

1978 The Merchants of Buenos Aires 1778-1810. Family and commerce. Cambridge. Cambridge University Press.

VArela, Consuelo

2013 "Microhistoria de un Galeón: El Santo Niño y Nuestra Señora de Guía (1684-1689)". En Bernabéu Albert - MARTínez-Shaw (eds.), Un océano de seda y plata: el universo económico del Galeón de Manila. Sevilla. CSIC, pp. 229-246.

Yuste, Carmen

2007 Emporios transpacificos. Comerciantes mexicanos en Manila, 1710-1815. México. UNAM. 